\title{
Workplace care: a sensible form of support to convalescents from occupational injuries or diseases
}

\author{
Markus Taddicken \\ Berufsgenossenschaft f. Gesundheitsdienst u. Wohlfahrtspflege (BGW) / German Social Accident Insurance, Germany. \\ markus.taddicken@bgw-online.de
}

In order to ensure the success of medical and occupational rehabilitation, the BGW - the occupational insurer offers its clients to accompany them at the workplace. This aims at transferring the working methods, which the rehabilitant has acquired during rehabilitation and are therefore partly new to him, into operational practice and at verifying their fitness for practical applicability. Apart from that, this shall facilitate to identify factors jeopardizing reintegration and to beneficially influence them, if possible.

Work is resumed with the approval by the client in question and their employer, accompanied by a specialized workplace attendant. Depending on the severity of the health impairment and on the prevailing contextual factors, such care is provided on an hourly or daily basis for one or up to several weeks.

Thereby, the workplace attendant refers the client to the most reasonable and gentle mode of working that is possible. Moreover, the workplace attendant takes care of potential difficulties arising during the stage of resuming employment, in order to work out strategies early on for ensuring the success of rehabilitation and for transferring such strategies to operational practice, jointly with all parties involved, including the BGW rehab managers.

The potential need for qualification, following the motto of "Occupational placement comes before qualification", is thereby identified at an early stage and in a purposeful way.

Principal Experience and Summary: Workplace care facilitates highly practice-oriented reintegration; Difficulties in the reintegration process are identified at an early stage; Workplace accompaniment gears prevention very effectively to rehabilitation. Clients as well as employers perceive such support provided by the BGW as being sensible and helpful. 